\title{
INDUSTRI MIKRO NUTRIENT BLOCK TERNAK RUMINANSIA
}

\author{
Winaruddin ${ }^{1}$, T.Z. Helmi ${ }^{2}$, Rusli ${ }^{3}$
}

\begin{abstract}
ABSTRAK
Tujuan pengabdian adalah untuk meningkatkan pengetahuan dan inovasi teknologi industri pada peternak, tentang penggunaan teknologi pakan ternak untuk meningkatkan produktivitas ternak ruminansia dan mendiskusikan tentang kelayakannya. Kegiatan telah dilakukan dari Agustus 2017 sampai Oktober 2017, dan dihadiri oleh 30 peternak dari 60 peserta yang ditargetkan. Dari anggota kelompok ternak di Kecamatan Krueng Barona Jaya, Kabupaten Aceh Besar. Metode yang digunakan adalah kursus pelatihan dan praktek kepada peternak. Tujuan pemberian nutrient block adalah untuk menyediakan secara konstan sumber nitrogen, vitamin dan mineral yang terdegradasi untuk mendorong pertumbuhan mikroba rumen, terutama pada ternak ruminansia yang diberi pakan hijauan berkualitas rendah. Campuran pakan mineral yang disiapkan sesuai spesifikasi yang digunakan untuk membuat nutrient block dengan proses dingin dam dicetak dengan mesin press tangan pembuat block. Ukuran bclok /pada kegiatan ini adalah $300 \mathrm{~mm}$ x $150 \mathrm{~mm}$ x 120 $\mathrm{mm}$ dengan berat $6 \mathrm{~kg}$. Dengan memberi makanan nutrient block pada sapi potong kelompok peternakan rakyat, menunjukkan bahwa skor bobot hidup dan kenaikan berat hidup meningkat. Hasil kegiatan menunjukkan bahwa sebagian besar peternak mengadopsi program teknologi baru pemberian pakan ternak.
\end{abstract}

Kata kunci : industri mikro, mesin press, nutrient block, ternak ruminansia.

\begin{abstract}
The objective of this community service is to improve the knowledge and innovation industry technology of farmers, about the using of livestock feeding technologies to improve ruminants productivity and discuss their feasibility. The activity have been conducted from August 2017 to October 2017, and attended by 30 farmers from 60 targeted participants. members of Beef Cattle in Krueng Barona Jaya district, Aceh Besar regency. The methods used were training course and practice to the farmers. The aim of nutrient block supplementation is to provide a constant source of rumen degradable nitrogen, vitamins and minerals to promote growth of rumen microbes especially in ruminants fed poor quality forage. Mineral mixture prepared as per specifications is being used for manufacturing nutrient blocks by the cold process in an hand press block-making machine. The size of the block for this project is $300 \mathrm{~mm}$ x $150 \mathrm{~mm}$ x $120 \mathrm{~mm}$ with a weight of $6 \mathrm{~kg}$. By feeding nutrient blocks to smallholder beef cattle in areas it was found that live-weight and body condition score tended to be improved. The results showed that a majority of farmers adopted the of the new technology livestock feeding programme.
\end{abstract}

Keywords: microindustry, press machine, nutrient block, ruminants.

${ }^{1}$ Staf Pengajar Fakultas Kedokteran Hewan Universitas Syiah Kuala, winaruddin@unsyiah.ac.id

${ }^{2}$ Staf Pengajar Fakultas Kedokteran Hewan Universitas Syiah Kuala, zahrial_fkh@unsyiah.ac.id

${ }^{3}$ Staf Pengajar Fakultas Kedokteran Hewan Universitas Syiah Kuala, drh.rusli.msi@gmail.com 


\section{PENDAHULUAN}

Industri peternakan sangat penting dalam penyediaan kebutuhan produk makanan berbasis hewani untuk gizi manusia, dan sebagai sumber pendapatan bagi banyak petani miskin di banyak negata berkembang seperti Indonesia. Asumsi bertambahnya populasi manusia dan pertumbuhan ekonomi, permintaan untuk produk-produk peternakan akan berlipat ganda dalam dua dekade mendatang. Namun, kendala pengembangan peternakan di Indonesia adalah kelangkaan dan fluktuasi kualitas dan kuantitas persediaan nutrisi ternak (Fariani dkk., 2014). Pakan merupakan salah satu faktor yang sangat berpengaruh terhadap produktivitas ternak. Apabila kekurangan pakan, baik secara kualitas maupun kuantitas dapat menyebabkan rendahnya produktivitas ternak yang dihasilkan. Meningkat populasi dan industrialisasi membuat lahan padang rumput sebagai sediaan pakan hijauan terus menyusut dan terdegradasi karena aktivitas manusia (Husain, 2015).

Menurut Delima dkk. (2017) sebagian besar peternakan rakyat ternak ruminansia di Kabupaten Aceh Besar berasal dari kelompok peternak kecil. Demikian pula sekitar 90\% peternak sangat bergantung pada pakan ternak yang tersedia secara alami dan hanya melimpah pada saat musim penghujan. Rumput alami adalah sumber utama makanan untuk ternaknya. Praktik yang umum digunakan adalah ternak merumput di padang rumput yang tidak sempurna. Selebihnya diberi limbah pertanian seperti jerami yang tidak diolah dengan sempurna. Pakan seperti ini tidak dapat mempertahankan berat badan ternak. Kehilangan berat badan selalu terjadi selama musim kemarau.

Untuk meningkatkan produktivitas ternak, suplementasi nutrient block perlu dilakukan agar dapat memperbaiki pemanfaatan pakan yang berkualitas rendah. Oleh karena itu, pengembangan nutrient block dinilai dapat memecahkan masalah di lapangan secara praktis. Nutrient block telah dikembangkan sebagai suplemen pakan yang dapat menghasilkan efek manipulasi rumen sehingga meningkatkan laju konversi pakan.

Menurut Lapauve dan Danbaro (2014), nutrient block menyediakan secara konstan sumber nitrogen, vitamin dan mineral yang terdegradasi untuk mendorong pertumbuhan mikroba rumen, terutama pada ternak ruminansia yang diberi pakan hijauan berkualitas rendah Pengembangan formula dan proses teknologi juga perlu disesuaikan dengan kondisi daerah peternakan, terutama kemudahan mencari bahan baku pakan yang potensial baik dari segi kualitas maupun kuantitas.

Tujuan pengabdian masyarakat ini adalah untuk meningkatkan pengetahuan dan keterampilan para peternak rakyat tentang nutrient block untuk meningkatkan produktivitas ternak ruminansia, terutama ternak sapi. Selain itu juga meningkatkan jiwa kewirausahaan para mitra dalam bentuk home industry pakan ternak dan peralatannya kepada masyarakat peternakan di Kecamatan Krueng Barona Jaya Kabupaten Aceh Besar.

Kegiatan ini sangat bermanfaat bagi para peternak yang kurang memperoleh pengetahuan dan keterampilan praktis, tentang teknologi nutrient block untuk meningkatkan produktivitas ternak. Diharapkan dapat mengatasi kekurangan pakan ternak dan menjaga kelangsungan usaha peternakan sekaligus meningkatkan kesejahteraan para peternak.

\section{METODE PELAKSANAAN}

Kegiatan dilakukan dari Agustus 2017 sampai Oktober 2017 di Kecamatan Krueng Barona Jaya Kabupaten Aceh Besar, dan dihadiri oleh 10 mahasiswa dan 30 peternak dari 60 peserta yang ditargetkan. Transfer teknologi dan adopsi oleh Tim Pelaksana kegiatan Pengabdian kepada Masyarakat dengan para mitra dilakukan melalui proses, mendengar, mengetahui, mencoba, mengevaluasi, menerima, meyakini, dan melaksanakan. Melalui proses ini inovasi teknologi dapat memenuhi target sasaran pada semua mitra. Para mitra mampu menganalisis peluang dan manfaat 
perkembangan usahanya secara ekonomis. Agar setiap proses berjalan dengan baik, penyampaian inovasi melalui tahapan penjelasan, diskusi, praktek serta pendampingan. Para mitra yang dilibatkan adalah pengusaha industri mikro pakan ruminansia, industri mikro logam dan kelompok peternak ruminansia, di Kabupaten Aceh Besar dan sekitarnya. Tahapan kegiatan sebagai berikut:

\subsection{Tahap I. Pengenalan bahan dan peralatan}

Pengenalan teknologi nutrient block untuk pengembangan usaha peternakan ruminansia (sapi, kerbau, kambing dan domba) yang berorientasi bisnis. Kepada mitra kelompok ternak dijelaskan tentang manfaat nutrient block untuk penggemukan sapi dalam masa pemeliharaan yang relatif pendek. Demikian juga manfaatnya pada sapi induk untuk mencegah gangguan reproduksi akibat kekurangan mineral. Penjelasan tentang bahan baku yang digunakan yaitu; urea, molasses, mineral mix, beras jagung, dedak, garam, kapur dan temulawak, serta manfaatnya dari masing-masing bahan.

Kepada mitra industri nutrient block diberikan perbaikan formula yang dapat memenuhi standar pakan suplemen dan peralatan yang lebih modern. Peralatan yang diperkenalkan adalah mesin press block dengan kemampuan produksi 100 block per hari dan peralatan pendukung lainnya. Seluruh peralatan diproduksi oleh mitra home industry logam, sehingga kebutuhan perawatan dan suku cadang tetap terjamin. Diharapkan kegiatan ini dapat membentuk industri nutrient block dengan produk yang kompetitif.

\subsection{Tahap II . Pengolahan nutrient block}

Prosedur pembuatan nutrient block sesuai dengan formula yang memenuhi standar gizi ternak ruminansia, dengan biaya produksi yang rendah. Para mitra diperkenalkan cara menyusun formula, mengolah dan mengoperasikan peralatan mesin press block, pengemasan dan cara pemberiannya pada ternak. Tabel 1 menunjukkan jumlah bahan yang akan dicampur untuk membuat nutrient block cara dingin dengan ukuran berat block 6 kilogram.

Tabel 2.1. Jumlah bahan untuk membuat ukuran $6 \mathrm{Kg}$ nutrient block.

\begin{tabular}{|c|c|c|c|}
\hline No. & Bahan & $\%$ & Kg \\
\hline 1 & Beras jagung & 25 & 1,50 \\
\hline 2 & Dedak & 25 & 1,50 \\
\hline 3 & Garam & 4 & 0,24 \\
\hline 4 & Kapur & 8 & 0,48 \\
\hline 5 & Mineral mix & 1 & 0,06 \\
\hline 6 & Molasses & 25 & 1,50 \\
\hline 7 & Tepung temulawak & 6 & 0,36 \\
\hline 8 & Urea & 6 & 0,36 \\
\hline \multicolumn{2}{|r|}{ Total } & 100 & $6,00 \mathrm{Kg}$ \\
\hline
\end{tabular}

Pembuatan nutrient block sangat mudah, sederhana dan pembuatannya terdiri atas empat tahap yaitu; persiapan komponen, pencampuran, pencetakan dan pengeringan. Sejumlah bahan ditimbang berdasarkan formula block. Selanjutnya urea ditambahkan ke dalam bejana yang berisi molasses dan diaduk merata selama 20 menit. Dengan menggunakan mixer; secara berurutan dedak, beras jagung,, temulawak, garam, kapur, dan mineral mix dicampur sampai merata. Campuran urea dan molasses ditambahkan secara perlahan ke dalam mixer sampai adonan berwarna seragam. 
Adonan ddicetak dengan mesin press block. Block hasil cetakan diangkat dan diletakkan pada rak pengering. Block dibiarkan kering selama 5 hari. Ukuran hasil cetakan nutrient block adalah 300 $\mathrm{mm} \times 150 \mathrm{~mm}$ x $120 \mathrm{~mm}$ dengan berat $6 \mathrm{Kg}$. Pemberian nutrient block pada ternak ruminansia secara jilatan dan dapat dihabiskan selama 18 hari.

Menurut Guesh dan Urge (2014), block harus dibuat cukup keras untuk memastikan bahwa ternak mendapatkan konsumsi zat gizi secara lambat yaitu melalui proses menjilat. Dengan demikian untuk konsumsi $300 \mathrm{~g}$ per hari dapat terpenuhi. Ringkasan rangkaian kegiatan ditunjukkan pada gambar 2.1.
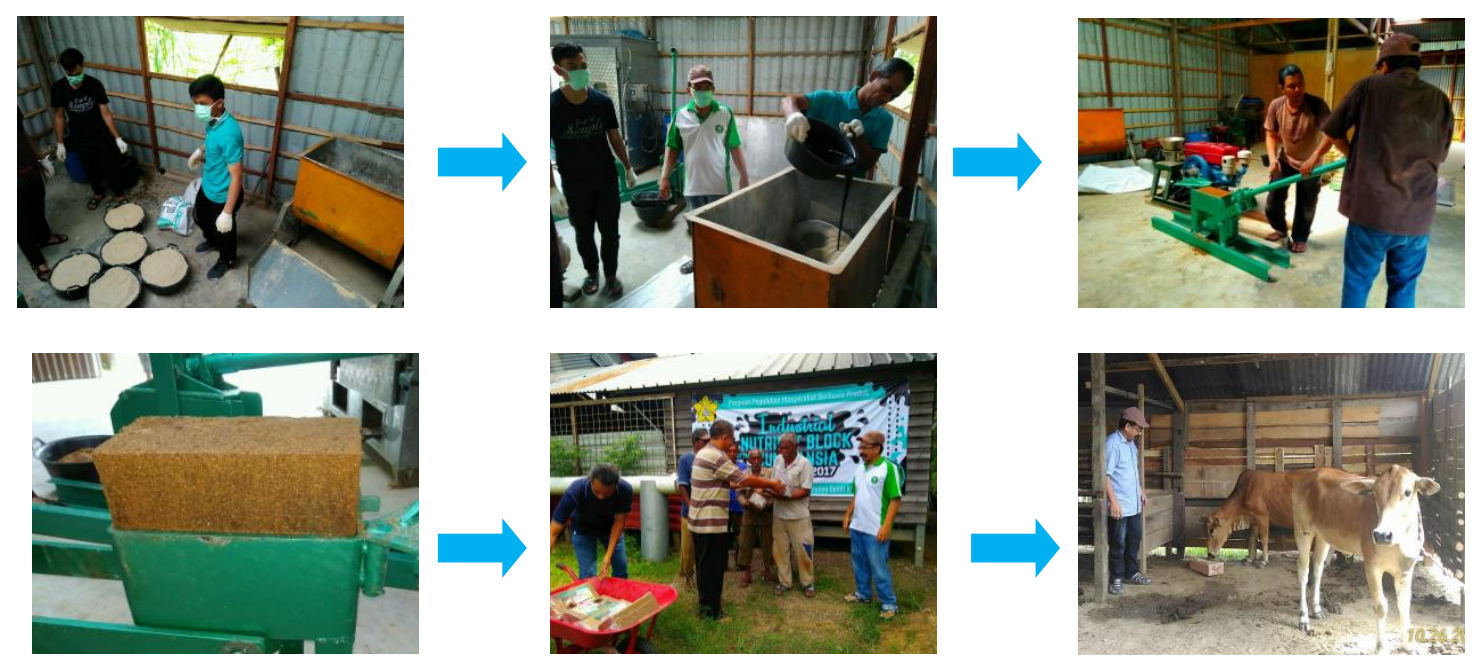

Gambar 2.1. Rangkaian kegiatan usaha industri mikro nutrient block ternak ruminasia.

\section{HASIL DAN PEMBAHASAN}

Selama pengabdian berlangsung respon dan partisipatif dari para mitra sangat tinggi. Kegiatan ini telah meningkatkan keterampilan peternak di bidang manajemen dan kesehatan ternak ruminansia, terutama ternak sapi. Para peternak melaporkan bahwa terjadi perbaikan pertambahan berat badan / kesehatan sapi setelah pemberian nutrient block.

Keberhasilan ini sejalan dengan pernyataan Arenu dkk. (2014), bahwa nutrient block dalam pakan ruminansia telah banyak digunakan oleh berbagai negara untuk meningkatkan produktivitasi ternak Pemberian terutama di peternakan yang sebagian besar bergantung pada pakan hijauan termasuk limbah pertanian dan padang rumput yang berkualitas rendah. Sangat disarankan agar teknologi nutrient block digunakan terutama pada peternakan rakyat dimana kualitas padang rumput sangat buruk. Nutrient block dapat menjadi agen efektif sebagai pakan suplemen pada ternak ruminansia.

Sebelum hadirnya kegiatan ini pembuatan nutrient block masih menggunakan alat yang sederhana yaitu kotak block yang terbuat dari kayu. Alat tersebut kurang menunjang kebutuhan nutrient block dalam jumlah banyak. Menurut Lapauve dan Danbaro (2014), selayaknya pada usaha peternakan rakyat memiliki mesin press yang mampu produksi minimal 50 block per hari. Umumnya alat yang digunakan adalah mesin press yang terbuat dari logam. Dimensi mesin cetakan dirakit sesuai dengan ukuran dan berat block dan jenis ternak ruminansia sasaran.

Untuk itu telah dibuat mesin press nutrient block yang praktis dengan harga yang relatip murah, yang digerakan dengan tangan. Disain mesin merupakan hasil pengembangan tim pengabdi bekerja sama dengan mitra industri mikro logam setempat. Melalui kerampilan ini mitra industri mikro 
logam dapat membantu para pelaku usaha industri mikro pakan yang memerlukan mesin tersebut. Menggunakan mesin press nutrient block kemampuan produksi dapat ditingkatkan. Peralatan sangat praktis sehingga mudah dioperasikan oleh mitra industri pakan, termasuk masalah perawatannya.

Kemampuan mesin press dapat memproduksi 100 nutrient block per hari, sehingga waktu dan tenaga mitra industri mikro pakan lebih efisien. Mitra industri mikro telah meendapatkan pengetahuan baru, terutama formula nutrient block sebagai growth promoter yang standar. Para kelompok peternak sepakat untuk memajukan industri pakan tersebut dengan membentuk unit-unit distribusi pakan. Pengabdian ini telah membantu usaha ekonomi yang sinergis dan saling menguntungkan dari para mitra binaan.

\section{KESIMPULAN DAN SARAN}

Melalui program pengabdian kepada masyarakat berbasis produk ini pengetahuan dan keterampilan para mitra tentang konsep dasar dan prinsip kerja, formula nutrient block, cara pembuatan, pengemasan dan pemberian telah mencapai sasaran. Supaya berkelajutan, perlu pendampingan dan pemantauan dari pemerintah daerah melalui dinas terkait.

\section{UCAPAN TERIMAKASIH}

Ucapan terima kasih ditujukan kepada Rektor dan Ketua Lembaga Penelitian dan Pengabdian kepada Masyarakat dan Universitas Syiah Kuala yang telah memfasilitasi dan mendanai kegiatan ini. Ucapan terimakasih juga ditujukan kepada Dekan Fakultas Kedokteran Hewan Universitas Syiah Kuala serta para mitra dan anggota tim pengabdian masyarakat atas kerjasamanya, sehingga kegiatan ini dapat terlaksana.

\section{DAFTAR PUSTAKA}

Arenu, J., Mumbiangke and G. Danbaro (2014). Growth of beef steers fed on urea-molasses-mineral block supplement in Papua New Guinea. Niugini Agrisaens. Vol.6, pp. 33-38.

Delima, M., Abubakar Karim, M. Yunus (2017). Kajian Potensi Produksi Hijauan Pakan pada Lahan Eksisting dan Potensial untuk Meningkatkan Populasi Ternak Ruminansia di Kabupaten Aceh Besar. Jurnal Agripet. Vol.15 (1), pp. 33-40

Fariani, A., S. Susantina, dan Muhakka (2014). Pengembangan Populasi Ternak Ruminansia Berdasarkan Ketersediaan Lahan Hijauan dan Tenaga Kerja di Kabupaten Ogan Komering Ulu Timur Sumatera Selatan. Jurnal Peternakan Sriwijaya. Vol. 3, No. 1, pp. 37-46.

Guesh, F. and M. Urge (2014). Comparison of supplementing urea-molasses block and urea-atela blocks on body weight change and carcass characteristics of male blackhead ogaden sheep fed natural pasture hay. J. Of Bio. Agric. and Health. Vol.4, No.20.

Husain, M. S. S. (2015). Analisis Bahan Kering dan Bahan Organik Wafer Limbah Jerami Klobot dan Daun Jagung Selama Penyimpanan. Skripsi, Fakultas Peternakan Universitas Hasanuddin, Makassar.

Lapauve, L and G. Danbaro (2014). Effects of Urea-Molasses-Mineral-Blocks (UMMB) on the growth performance of goats (Capra hircus) maintained on natural pastures in Papua New Guinea. PNG. J. of Agric. Forest. and Fish. Vol.55, pp. 31-37. 